Journal of Systems Science and Information

Apr., 2017, Vol. 5, No. 2, pp. 111-127

DOI: $10.21078 /$ JSSI-2017-111-17

\title{
Optimal Implementation Strategy of Carbon Emission Reduction Policy Instruments in Consideration of Cost Efficiency
}

\author{
Xiangfei LI \\ School of Management, Tianjin Polytechnic University, Tianjin 300387, China \\ E-mail: soar.li@163.com \\ Qin QIN \\ School of Management, Tianjin Polytechnic University, Tianjin 300387, China \\ E-mail: belinda8093@163.com \\ Yang GAO \\ College of Management and Economics, Tianjin University, Tianjin 300072, China \\ E-mail: gaoyang19871026@163.com
}

\begin{abstract}
In this paper, regulatory and optimum programming model has been adopted. Considering the costs of emission reduction, supervision and penalty, we went all out to analyze the optimal decision of cost efficiency of regulators when implementing these three policy instruments: carbon emission standards, carbon emission trading permissions, and carbon taxes as well. Its result has indicated: In strict accordance with control target of total carbon emissions, regulators are willing to render social and economic cost able to achieve the goal of optimal cost efficiency by regulating carbon emission standards and supervising marginal cost caused by variations in the probability; fortunately, under the conditions of low supervisory cost and certain criteria which is met, the implementation of carbon emission trading permissions could provide social and economic cost with opportunities to realize that objective; through comparative analysis, carbon emission trading permissions have the advantages of higher efficiency than carbon emission standards on the premise of incomplete information. During the implementation of carbon taxes strategy, when there exists uncertainty information in the enterprises reduction behaviors, the condition which enterprises can fully comply with is the tax rate level is not higher than marginal penalty function; the tax rate level of enterprises perfect compliance ought not to be lower than the division of marginal penalty cost and marginal supervisory cost. The optimal strategy of enterprises imperfect compliance is that regulators varying the marginal cost of emission standards is equal to varying that of supervisory probability.
\end{abstract}

Keywords carbon emission reduction; cost efficiency; carbon emission standard; carbon emission trading permission; carbon tax

\section{Introduction}

Environmental policy instruments have gradually become a hot issue which is studied in the field of environmental economics, since Arthur Pigou put forward that we are ought to solve the

Received February 13, 2016, accepted April 3, 2016

Supported by the National Natural Science Foundation of China (71503178) 
externality of environment by means of system design on the basis of neoclassical economics ${ }^{[1]}$. At the global climate conference in Copenhagen, China has committed that carbon dioxide emissions are about to drop 40\% 50\%, compared with 2005. Faced with tremendous pressure of reducing emissions, how to design and implement not merely scientific but effective carbon emissions reduction policy instruments, guide each side to coordinate and reduce carbon emissions voluntarily, realize the sustainable development of economy as well have been well seen as extremely vital issues which are indeed in need to be tackled at present in China. Enterprises' voluntary reduction, optimal configurations of assets and the achievement of guiding real economy to make the switch to low-carbon economy have already been come true, with the use of market mechanism in the EU-ETS system which was established by European Union in 2005. Nevertheless, traditional command-and-control environmental policy instruments still hold sway in China nowadays, there exists a wide gap compared with developed countries, especially in the aspects of designation and implementation of market-oriented carbon emissions reduction policy instruments. It mainly shows in 'the high cost of corporate law-abiding and of implementation of supervisory departments, the low cost of corporate violations' and so forth ${ }^{[2]}$. One of the capital reasons is that the scale and number have only been taken into consideration in the choices of traditional carbon emission policy instruments, failing to bring the matter of social and economic cost efficiency into decision-making category. As a consequence, it is of essentially practical significance to research carbon emission policies from the perspective of implementation cost.

Environmental policy instruments have been well received as the concrete environmental measures which are implemented by environmental regulators for coping with environmental pollution problems, the more pervasive environmental policy instruments embrace pollution emission standard, pollution emission trading permission, environment tax (included by carbon $\operatorname{tax}$, environmental subsidy and its like ${ }^{[3]}$. With the appearance of problems of high social and economic cost which are produced by environmental regulation, academia has increasingly laid great emphasis on the study of cost efficiency of environmental policy. In the early 1970s, the United States proposed a scientific method which is used to research on regulation based on cost-benefit analysis, firstly evaluating environmental policy instruments in terms of cost efficiency systematically ${ }^{[4,5]}$. Harford has studied the effects on the enterprises emission reduction cost which bred by effluent standard and effluent tax for the first time under the condition of enterprises imperfect compliance permitted ${ }^{[6]}$. Helfand has been under the impression that 'command-and-control' policy instruments can afford diverse types of enterprises with the same contamination control responsibility so as to meet environmental targets, but less concern was given to implementation cost in regulation ${ }^{[7]}$. Mliak has compared cost efficiency of emission standard with that of emission trading permission under a certain amount of emissions constraints and the circumstance of regulators grasping perfect information towards enterprises, contended that the implementation cost of emission trading permission was higher than it of emission standard $^{[8]}$. Nonetheless, he has not taken penalty cost into account in that his assumption was accomplished under the situation of enterprises perfect compliance. Hahn and Axtell have compared implementation cost of emission standard with that of emission trading permission on condition that enterprises non-compliance to a degree was permitted, but 
left supervisory cost and penalty cost out of consideration ${ }^{[9]}$. Stranlund has researched on implementation conditions which make enterprises emission reduction cost realize optimal cost efficiency in the emission trading permission condition. In order to let total cost of emission reduction achieve minimization, he presented that regulators could make good use of constant marginal penalty to guide enterprises ${ }^{[10]}$. And Arguedas has studied the implementation conditions with the same aim on condition of emission standard in a sole typical enterprise and hypothesis model which regulators have perfect information about this enterprise. He pointed out that if regulators have had the choices to penalize structure, then linear penalty would have directed enterprises to fully comply with emission standard-the lowest total cost ${ }^{[11]}$. These two types of instruments-carbon tax and carbon emission trading permission-have been in contrast by Adly, he hold the view that both of them can lead enterprises emission reduction cost to the minimum under the situation of perfect information and without uncertainty. If thinking over these issues-uncertainties of future, tax distortions, income distribution effects, etc, those two kinds of instruments' utilities will differ sharply ${ }^{[12]}$; Chávez has assumed that implementation cost of emission trading permission and emission standard under the enterprises perfect compliance was respectively lower than that under the enterprises non-compliance through studying. Besides that, the implementation cost of emission trading permission was no lower than that of emission standard ${ }^{[13]}$; based on Chávez' research, Caffera has argued that cost of emission trading permission was no less than that of emission standard on the premise of perfect information $^{[14]}$. Domestic research concerning cost efficiency of environmental policy instruments is quite few, researches involved environmental policy instruments cost are mainly showed in the following literature. Li, Song and others have made extensive use of environmental production function and environmental directional distance function to analyze environmental regulation cost of Chinese provinces, it suggested that in the circumstance of environmental regulation currently, there being much more higher environmental regulation cost in a good many provinces in China ${ }^{[15]}$. Xu and He have made an analysis of implementation cost of different emission reduction policy instruments with others by the comparative research method, advocated that it is of possibility to improve technology of carbon emission reduction in the enterprises on condition of total emissions control, the implementation cost of pollution tax was equal to that of more than emission reduction subsidy, but emission standard as well, and that of emission trading permission has been well seen as the lowest ${ }^{[16]}$. Jin and Sheng have been convinced that the targets of maximization of social welfare and effective regulatory regime of supervisory cost kept consistent in the restriction of total control ${ }^{[2]}$.

As has been stated, the following deficiencies are mainly embodied in the current research: Namely, 1) failing to consider about cost efficiency of carbon emission reduction policy instruments in existing research, the majority of them have brought the promotion of enterprises production decision and technology incentive into focus; 2) there are few research regarding cost efficiency of carbon emission reduction policy instruments while pondering over emission reduction cost, supervisory cost and penalty cost simultaneously; 3) comparative research on cost efficiency which implementing various genre of carbon emission reduction policy instruments under imperfect information is much more less. Based on the demerits mentioned above and previous researches, this paper intended to attach considerable attention to emission reduction 
cost, meanwhile, supervisory cost as well as penalty cost under control of total carbon emission from cost efficiency point of view, discussing about the optimal decision-making of cost efficiency in the implementation of carbon emission standard, carbon emission trading and carbon tax. On this basis, it has made a comparison of cost efficiency of carbon emission standard and carbon emission trading in the case of imperfect information and optimal condition of carbon tax strategy on the occasion of marginal penalty cost regulated. The research is making an attempt to offer a new perspective and learning reference for the designation, implementation and choices of carbon emission reduction policy instruments in China.

\section{Basic Settings of Theoretical Model}

There being $n$ risk-neutral enterprises set up in a competitive market. When regulators start implementing carbon emission reduction policy instruments, enterprises will have an inclination to mull over the issue of carbon emission in view of cost minimization, in addition, they possess imperfect information about enterprises. Abatement cost function of enterprise $i$ is $c_{i}\left(e_{i}\right), e_{i}$ shows the carbon emission of enterprise $i$. Setting that abatement cost function is strictly decreasing convex function to carbon emission, that is to say: $c_{i}^{\prime}\left(e_{i}\right)<0, c_{i}^{\prime \prime}\left(e_{i}\right)>0$. Parameter $\theta$ represents carbon emission reduction technological level of enterprises and meets the requirement of $\theta \in\left[\theta_{1}, \theta_{2}\right]\left(0<\theta_{1}<\theta_{2}\right)$. The smaller $\theta$ is, the more competent enterprises' emission reduction capabilities are, the lower cost is in the situation of pollution emission; on the contrary, the bigger $\theta$ is, the less competent enterprises' emission reduction capabilities are, the higher cost is in the situation of pollution emission. Setting conditions must be resolved to be satisfied in three kinds of dissimilar policy instruments are:

1) Under the condition of carbon emission standard, regulators are to set a standard $s_{i}$ of carbon emission in accordance with carbon emission of enterprise $i, E$ means top thread of total carbon emissions, satisfying $\sum s_{i}=E$. When carbon emission which enterprise $i$ reported has surpassed prescribed discharge standard $v_{i}$, then $v_{i}=e_{i}-s_{i}$. For rational persons, $v_{i} \geq 0$. When $v_{i}=0$, it proves that enterprise $i$ perfectly comply with environmental policy; when $v_{i}>0$, it manifests that enterprise $i$ imperfectly comply with environmental policy.

2) Under the condition of carbon emission trading permission, the total carbon emissions permits issued by government is recorded as $L$, and satisfying $L=E$. Suppose that each enterprise made a deal of emission permits in a competitive carbon emission trading market, it would produce an equilibrium price $p^{*}$. Assume that $l_{i}{ }^{0}$ means the number of emission permits of enterprise $i$ which issued by government initially, and $l_{i}$ means the number of emission permits which be possessed, when enterprise $i$ lack of adherence to emission standard, in other words, when $v_{i}=e_{i}-l_{i}>0$, emission load exceeded to holding amount of emission permits, that indicates $v_{i}=e_{i}-l_{i}>0$.

3) Under the condition of carbon tax levied, set that rate of carbon emission which levied for enterprise $i$ is $t$, regulators ask for enterprises to report the emission plan in advance, the reported number is set up $r_{i}$. So the portion of the amount of enterprises actual emission outstrip that of reported is $v_{i}=e_{i}-r_{i}$. When enterprise $i$ disobey carbon tax implementation, $v_{i}=e_{i}-r_{i}>0$, put it another way, the actual carbon emission load superior to reported emission level. 
Regulators will make irregular examinations of the situation of enterprise $i$ carbon emission during implementation of three policies, test possibility is $\pi_{i}$. The greater $\pi_{i}$ is, the more effective government regulation is, the more ineffective on the converse. If finding out that the actual carbon emissions of enterprise $i$ is in excess of emission standard, then it would be confronted with fine and punishment. Here penalty function is $f\left(v_{i}\right)$, it signifies that functional relations of imposing a fine on violating enterprise $i$ and carbon emissions, setting that penalty function is in regard to strictly increasing convex function of carbon emissions, meeting $f(0)=$ $0, f^{\prime}(0)>0, f^{\prime \prime}(0)>0$. Unit cost of supervision caused by that is $\mu_{i}$, unit penalty cost is $\xi_{i}$. What is worth noticing is that penalty function is set as $F(v)=F_{0}+f(v)$ in other literature, and $F_{0}$ represents fixed amount of penalty. But that as it may, this form of penalty function is seldom used in the literature, what's more, according to Arguedas's research in reference [11], it declares that the section of fixed penalty is incapable of leading enterprises perfect compliance to obtain optimization under the policy instrument of emission standard, thus, penalty function should be set as $f(v)$ here.

\section{Model of Enterprises Compliance in the Implementation of Policy Instruments}

In order to analyze and implement specific carbon emission policy instruments, actions which are probably taken under the implementation of varied carbon policy instruments are resolved to be discussed about in the very beginning. This section has mainly explored enterprises behavioral model under the three types of carbon emission policy instruments.

\subsection{Enterprises Behavioral Model in Carbon Emission Standard}

During the implementation of carbon emission standard in enterprise $i$, regulators will irregularly check up on enterprises actual carbon emissions. If finding out that the actual carbon emissions of enterprise $i$ is in excess of emission standard, then it would be confronted with fine and punishment. Here penalty function is $f\left(v_{i}\right)$, it signifies that functional relations of imposing a fine on violating enterprise $i$ and carbon emissions. From the above assumptions, we are able to know that optimal emission reduction behavior of enterprise $i$ can be expressed as:

$$
\begin{array}{ll}
\min & c(e, \theta)+\pi f(e-s) \\
\text { s.t. } & e-s \geq 0 .
\end{array}
$$

Lagrange equation for problem (1) is: $\Lambda=\mathrm{c}(e, \theta)+\pi f(e-s)-\beta(e-s)$, the requirements of Kuhn-Tucker are

$$
\left\{\begin{array}{l}
\frac{\partial \Lambda}{\partial \mathrm{e}}=c_{e}(e, \theta)+\pi f^{\prime}(e-s)-\beta=0, \\
\frac{\partial \Lambda}{\partial \mathrm{e}}=\mathrm{s}-e \leq 0 ; \quad \beta \geq 0 ; \quad \beta(e-s)=0 .
\end{array}\right.
$$

\subsection{Enterprises Behavioral Model in Carbon Emission Trading}

In terms of enterprise $i$, the implementation of carbon emission trading is just like that of carbon emission standard to some extent, there still remaining possibilities of being reviewed by government regulators. As a result, if checking out any irregularity of that enterprise, it will be 
severely punished. Then the emission standard which directing enterprise $i$ to comply with in the case of carbon emission trading is about to be assumed that $p \leq f^{\prime}(0)$. Because enterprise $i$ will make a choice to purchase or sell carbon emission permits in the market. Hence, the optimal emission reduction behavior of enterprise $i$ could be remarked as

$$
\begin{array}{ll}
\min & c(e, \theta)+\pi f(e-s) \\
\text { s.t. } & e-s \geq 0 .
\end{array}
$$

Lagrange equation for (3) is: $K=c(e, \theta)+p\left(l-l_{0}\right)+\pi f(e-l)-\lambda(e-l)$; then the requirements of Kuhn-Tucker are

$$
\left\{\begin{array}{l}
\frac{\partial K}{\partial e}=c_{e}(e, \theta)+\pi f^{\prime}(e-l)-\lambda=0 \\
\frac{\partial K}{\partial e}=p-\pi f^{\prime}(e-l)+\lambda=0 \\
\frac{\partial K}{\partial e}=l-e \leq 0 ; \quad \lambda \geq 0 ; \quad \lambda(l-e)=0 .
\end{array}\right.
$$

\subsection{Enterprises Behavior Model in Carbon Tax}

Regulators possess imperfect information towards cost of emission reduction of enterprises. Suppose that the abatement cost function of enterprise $i$ is $c\left(e_{i}, \varepsilon_{i}\right)$, it has been well seen as strictly decreasing, furthermore, its discharge $e_{i}$ is strict convex function. And $\varepsilon_{i}$ means dominant index set, what is needed to place great emphasis on is that functional form of abatement cost for all the enterprises is consistent. Yet, as the variation of $x_{i}$ and $\varepsilon_{i}$, separate abatement cost is different as well ${ }^{[17]}$. The carbon tax rate of enterprise $i$ is $t_{i}$. If enterprises with heavy emission are discovered by government after inspection that the actual carbon emissions $e_{i}-r_{i}>0$, it is going to take a certain degree of economic penalty, and the penalty function is $f\left(v_{i}\right)$ here. Assume that $f\left(v_{i}\right)>t_{i}$. Accordingly, the optimal emission reduction behavior of enterprise $i$ is: $\Lambda=c_{i}\left(e_{i}, \varepsilon_{i}\right)+t_{i} r_{i}+\pi_{i} f\left(v_{i}\right)+\lambda_{i}\left(v_{i}\right)$. Among that, $\lambda_{i}$ is multiplication factor of constraints $v_{i} \geq 0$, according to the requirements of Kuhn-Tucker:

$$
\left\{\begin{array}{l}
\Lambda_{e}=\frac{\partial c_{i}}{\partial e_{i}}+\pi_{i} f^{\prime}\left(v_{i}\right)+\lambda_{i}=0, \\
\Lambda_{r}=t_{r}-\pi_{i} f^{\prime}\left(v_{i}\right)-\lambda_{i}=0, \quad r_{i} \geq 0, \quad r_{i}\left(t_{r}-\pi_{i} f^{\prime}\left(v_{i}\right)+\lambda_{i}\right)=0 \\
\Lambda_{\lambda}=-\left(e_{i}-r_{i}\right) \leq 0, \quad \lambda_{i} \geq 0, \quad \lambda_{i}\left(e_{i}-r_{i}\right)=0
\end{array}\right.
$$

As a consequence, when it makes no difference of enterprises observance or non-observance, they are usually to be defaulted to comply with consciously, the optimal reported emission strategy can be deduced from the above equation is

$$
r_{i}= \begin{cases}e_{i}, & \text { if } t_{i} \leq \pi_{i} f^{\prime}\left(v_{i}\right), \\ 0, & \text { if } t_{i}>\pi_{i} f^{\prime}\left(v_{i}\right) .\end{cases}
$$

Therefore, when $t_{i} \leq \pi_{i} f^{\prime}\left(v_{i}\right)$, namely when carbon tax is not exceeded expected marginal penalty, enterprise $i$ will faithfully report the emission load. When $t_{i}=\pi_{i} f^{\prime}\left(v_{i}\right)$, marginal 
abatement cost selected by enterprises is equal to carbon tax rate, which means $-c_{i}^{\prime}=t_{i}$. However, when $t_{i}>\pi_{i} f^{\prime}\left(v_{i}\right)$, enterprise would probably give false information about emission load. When $\lambda_{i}=0$, there will be $-c_{i}^{\prime}=\pi_{i} f^{\prime}\left(v_{i}\right)$ inferred from equations of $(4) \sim(9)$, so the marginal abatement cost chose by non-compliance enterprises is equivalent to its marginal penalty. Put it another way, emission behavior of enterprise $i$ will be like this

$$
e_{i}= \begin{cases}e\left(\mathrm{t}_{i}\right)_{i}, & \text { if } t_{i} \leq \pi_{i} f^{\prime}\left(v_{i}\right), \\ e\left(\pi_{i} f^{\prime}\left(v_{i}\right)\right), & \text { if } t_{i}>\pi_{i} f^{\prime}\left(v_{i}\right) .\end{cases}
$$

Here $e_{i}=e_{i}(\cdot)$ represents the actual emission function of enterprises.

\section{Analysis of Optimal Cost Efficiency Decision-Making by Regulators}

\subsection{Analysis of Optimal Cost Efficiency Decision-Making in Carbon Emission Standard}

In the implementation of carbon emission standard, regulators are willing to make socioeconomic costs minimized so as to obtain the abatement aim of total carbon emissions being deemed as $E$. This socioeconomic costs cover enterprises' abatement costs and regulators' enforcement cost, meanwhile, enforcement costs include not only monitoring costs for enterprises $\mu_{i} \pi_{i}$, but also sanctioning $\operatorname{costs} \xi_{i} \pi_{i} f\left(v_{i}\right)$. Then the optimal enterprises' planning is

$$
\begin{array}{ll}
\min _{\substack{\left(s_{1}, s_{2}, \cdots s_{n}\right) \\
\left(\pi_{1}, \pi_{2}, \cdots \pi_{n}\right)}} & \sum_{i=1}^{n}\left(c_{i}\left(e_{i}\right)+\mu_{i} \pi_{i}+\xi_{i} \pi_{i} f\left(e_{i}-s_{i}\right)\right) \\
\text { s.t. } & e_{i}=e_{i}\left(s_{i}, \pi_{i}\right) \\
& \sum_{i=1}^{n} e_{i}\left(s_{i}, \pi_{i}\right)=E \\
& e_{i} \leq s_{i}, \quad \forall i=1,2, \cdots, n .
\end{array}
$$

Enterprises' abatement costs can be written as $\sum_{i=1}^{n} c_{i}\left(e_{i}\right)$, monitoring costs as $\sum_{i=1}^{n} \mu_{i} \pi_{i}$, sanctioning costs as $\sum_{i=1}^{n} \xi_{i} \pi_{i} f\left(e_{i}-s_{i}\right)$. Suppose that penalty function $f\left(e_{i}-s_{i}\right)$ is an exogenous variable for regulators, then Lagrangian function which established by regulators for figuring out the problem is

$$
\Lambda=\sum_{i=1}^{n}\left(c_{i}\left(e_{i}\right)+\mu_{i} \pi_{i}+\xi_{i} \pi_{i} f\left(e_{i}-s_{i}\right)\right)+\lambda\left[\sum_{i=1}^{n} e_{i}-E\right]
$$

Requirements of Kuhn-Tucker are

$$
\left\{\begin{array}{l}
\frac{\partial \Lambda}{\partial s_{i}}=c_{i}^{\prime}\left(e_{i}\right) \frac{\partial e_{i}}{\partial s_{i}}+\xi_{i} \pi_{i} f^{\prime}\left(e_{i}-s_{i}\right)\left(\frac{\partial e_{i}}{\partial s_{i}}-1\right)+\lambda \frac{\partial e_{i}}{\partial s_{i}}=0 \\
\frac{\partial \Lambda}{\partial \pi_{i}}=c_{i}^{\prime}\left(e_{i}\right) \frac{\partial e_{i}}{\partial \pi_{i}}+\mu_{i}+\xi_{i}\left(f\left(e_{i}-s_{i}\right)+\pi_{i} f^{\prime}\left(e_{i}-s_{i}\right) \frac{\partial e_{i}}{\partial \pi_{i}}\right)+\lambda \frac{\partial e_{i}}{\partial \pi_{i}}=0 \\
\frac{\partial \Lambda}{\partial \lambda}=\sum_{i=1}^{n} e_{i}-E=0, \quad \lambda \geq 0, \quad \forall i=1,2, \cdots, n .
\end{array}\right.
$$

From what has been analyzed above, we may safely draw the conclusion that: 
Proposition 1 Under the case of enterprises perfect compliance, the optimal cost efficiency could be gained by socioeconomic costs when the increased marginal sanctioning costs through lowering emission standard by regulators is no lower than the decreased marginal monitoring costs through reducing supervision probability, which meeting:

$$
\mu_{i} f(0) \leq \xi_{i}\left(f^{\prime}(0)\right)^{2} .
$$

Proof Under the condition of enterprises perfect compliance, that is when $e_{i}-s_{i} \leq 0$, we can infer from Equation (6):

$$
\frac{\partial e_{i} / \partial s_{i}}{\partial e_{i} / \partial \pi_{i}}=\frac{\xi_{i} \pi_{i} f^{\prime}\left(e_{i}-s_{i}\right)}{-\mu_{i}-\xi_{i} f\left(e_{i}-s_{i}\right)}
$$

Since the optimal discharge requirement of enterprise in the implementation of carbon emission standard is $-c_{i}{ }^{\prime}\left(e_{i}\right) \leq \pi_{i} f^{\prime}\left(e_{i}-s_{i}\right)^{[18]}$, so the partial derivatives of $\pi_{i}$ and $s_{i}$ from each side are like these in the following:

$$
\begin{aligned}
& \frac{\partial e_{i}}{\partial \pi_{i}}=\frac{-f^{\prime}\left(e_{i}-s_{i}\right)}{c_{i}\left(e_{i}-s_{i}\right)+\pi_{i} f\left(e_{i}-s_{i}\right)}<0, \\
& 0<\frac{\partial e_{i}}{\partial s_{i}}=\frac{\pi_{i} f\left(e_{i}-s_{i}\right)}{c_{i}\left(e_{i}-s_{i}\right)+\pi_{i} f\left(e_{i}-s_{i}\right)}<1 .
\end{aligned}
$$

Because when carbon emissions under standard which we set is identical with enterprises carbon emissions, monitoring resources which taken advantage of by regulators will realize optimal distribution, enforcement cost is of the highest cost efficiency, which is to achieve $e_{i}=s_{i}$, then there will appear $-c_{i}^{\prime}\left(e_{i}\right)=-c_{i}^{\prime}\left(s_{i}\right) \leq \pi_{i} f^{\prime}(0)$, we can acquire the result by putting the equations of (13) and (14) into (12):

$$
\frac{\partial e_{i} / \partial s_{i}}{\partial e_{i} / \partial \pi_{i}}{ }_{e_{i}=s_{i}}=\frac{\pi_{i} f(0)}{c_{i}\left(s_{i}\right)+\pi_{i} f(0)} \cdot \frac{c_{i}\left(s_{i}\right)+\pi_{i} f(0)}{-f^{\prime}(0)}=\frac{\pi_{i} f(0)}{-f^{\prime}(0)}=\frac{\xi_{i} \pi_{i} f^{\prime}(0)}{-\mu_{i}-\xi_{i} f(0)} .
$$

Due to $f(0)=0$ from the above, and $f(0) \rightarrow 0^{+}, \pi_{i} \geq 0$, so $\mu_{i} f(0) \leq \xi_{i}\left(f^{\prime}(0)\right)^{2}$. To sum up, Proposition 1 has been proved.

Left side of Equation (11) indicates that marginal monitoring costs decline with the descent of monitoring probability $\pi_{i}$ of regulators, while the right side denotes that marginal monitoring costs increase when regulators lower the carbon emission standard. Proposition 1 illustrates that when monitoring costs distinct from sanctioning costs of $n$ enterprises, the increased marginal monitoring costs via lowering carbon emission standard by regulators are no less than the decreased marginal monitoring costs by means of reducing monitoring probabilities so that we can lead socioeconomic costs to achieve optimal cost efficiency.

Proposition 2 Under the condition of enterprises imperfect compliance, regulators varying marginal costs in carbon emission standard is same as varying marginal costs of monitoring probability, with the assumption that the sum of marginal costs and sanctioning costs of $\pi_{i}$ which varied by regulators are equal to marginal sanctioning costs by varying $s_{i}$, which let total costs attain optimal cost efficiency, that is to meet:

$$
\frac{\mu_{i}+\xi_{i} f\left(e_{i}-\tilde{s}_{i}\right)}{\partial e_{i} / \partial \pi_{i}}=\frac{-\xi_{i} \tilde{\pi}_{i} f\left(e_{i}-\tilde{s}_{i}\right)}{\partial e_{i} / \partial s_{i}}, \quad i=1,2, \cdots, n
$$


Proof In the situation of enterprises imperfect compliance, namely, $e_{i}>\tilde{s}_{i}$. Here $\tilde{s}_{i}$ is the optimal emission standard that set by regulators according to the circumstance of enterprise $i$ carbon emission. We can gain the correlative requirements of Kuhn-Tucker as Equations (6) and (7) from what we have known already, in the meantime, Equations (6), (7) divided by $\partial e_{i} / \partial s_{i}$ and $\partial e_{i} / \partial \pi_{i}$ are

$$
c_{i}^{\prime}\left(e_{i}\right)+\frac{\mu_{i}}{\partial e_{i} / \partial \pi_{i}}+\frac{\xi_{i} f^{\prime}\left(e_{i}-s_{i}\right)}{\partial e_{i} / \partial \pi_{i}}+\xi \pi_{i} f^{\prime}\left(e_{i}-s_{i}\right)=-\lambda .
$$

The result is got from Equation (15):

$$
\frac{\mu_{i}+\xi_{i} f\left(e_{i}-\tilde{s}_{i}\right)}{\partial e_{i} / \partial \pi_{i}}=\frac{-\xi_{i} \tilde{\pi}_{i} f\left(e_{i}-\tilde{s}_{i}\right)}{\partial e_{i} / \partial s_{i}}, \quad i \neq j, \quad i, j=1,2, \cdots, n .
$$

If enterprise $i$ does not fully comply with the optimal implementation decision-making $\left(\tilde{\pi}_{1}, \tilde{\pi}_{2} \cdots, \tilde{\pi}_{n}, \tilde{s}_{1}, \tilde{s}_{2}, \cdots, \tilde{s}_{n}\right)$, then regulators need to make marginal emission costs and the sum of monitoring costs of each enterprise equal, based on that, we can deduce further about Equation (15) as follows:

$$
\begin{gathered}
c_{i}^{\prime}\left(e_{i}\right)+\xi_{i} \tilde{\pi}_{i} f^{\prime}\left(e_{i}-\tilde{s}_{i}\right)\left(\frac{\partial e_{i} / \partial s_{i}-1}{\partial e_{i} / \partial s_{i}}\right)=c_{j}^{\prime}\left(e_{j}\right)+\xi_{j} \tilde{\pi}_{j} f^{\prime}\left(e_{j}-\tilde{s}_{j}\right)\left(\frac{\partial e_{j} / \partial s_{j}-1}{\partial e_{j} / \partial s_{j}}\right), \\
\begin{array}{c}
c_{i}^{\prime}\left(e_{i}\right)+\frac{\mu_{i}}{\partial e_{i} / \partial \pi_{i}}+\frac{\xi_{i} f\left(e_{i}-\tilde{s}_{i}\right)}{\partial e_{i} / \partial \pi_{i}}+\xi_{i} \tilde{\pi}_{i} f^{\prime}\left(e_{i}-\tilde{s}_{i}\right)= \\
c_{j}^{\prime}\left(e_{j}\right)+\frac{\mu_{i}}{\partial e_{j} / \partial \pi_{j}}+\frac{\xi_{j} f\left(e_{j}-\tilde{s}_{j}\right)}{\partial e_{j} / \partial \pi_{j}} \\
+\xi_{j} \tilde{\pi}_{j} f^{\prime}\left(e_{j}-\tilde{s}_{j}\right) .
\end{array}
\end{gathered}
$$

As a consequence, Proposition 2 has been proved.

Just as what Equation (19) has shown above, Proposition 2 has proved that the sum of marginal abatement costs and sanctioning costs of movement $s_{i}$ should be the same in all over the enterprises; as what Equation (20) has illustrated above, the sum of marginal costs, monitoring costs and sanctioning costs as well of variation $\pi_{i}$ are identical in whole enterprises. As a result, the optimal implementation decision-making of cost efficiency by regulators under the condition of enterprises imperfect compliance will be like this: Varying marginal costs of supervision probabilities has the same meaning as varying marginal costs in carbon emission standard.

\subsection{Analysis of the Optimal Decision-Making of Cost Efficiency in Carbon Emis- sion Trading Permission}

In the circumstance of carbon emission trading permission, in order to direct socioeconomic costs to attain cost efficiency, regulators' optimal planning is being like this:

$$
\begin{array}{ll}
\underset{\substack{\left(v_{1}, \cdots, v_{n}\right) \\
\left(\pi_{1}, \cdots, \pi_{n}\right)}}{\min } & \sum_{i=1}^{n} c_{i}\left(v_{i}+l_{i}\left(p^{*}, \pi_{i}\right)\right)+\sum_{i=1}^{n} \mu_{i} \pi_{i}+\sum_{i=1}^{n} \pi_{i} \xi_{i} f\left(v_{i}\right) \\
\text { s.t. } & \sum_{i=1}^{n} v_{i}+l_{i}\left(p^{*}, \pi_{i}\right)=E, \quad v_{i} \geq 0, \quad i=1,2, \cdots, n .
\end{array}
$$

Lagrangian function for this issue is

$$
\Lambda=\sum_{i=1}^{n} c_{i}\left(v_{i}+l_{i}\left(p^{*}, \pi_{i}\right)\right)+\sum_{i=1}^{n} \mu_{i} \pi_{i}+\sum_{i=1}^{n} \pi_{i} \xi_{i} f\left(v_{i}\right)+\lambda\left(\sum_{i=1}^{n} v_{i}+l_{i}\left(p^{*}, \pi_{i}\right)-E\right) .
$$


The requirements of Kuhn-Tucker are

$$
\begin{aligned}
& \frac{\partial \Lambda}{\partial \pi_{i}}=c_{i}^{\prime}(\cdot)\left(\frac{\partial l_{i}}{\partial p^{*}} \frac{\partial p^{*}}{\partial \pi_{i}}+\frac{\partial l_{i}}{\partial \pi_{i}}\right)+\mu_{i}+\xi_{i} f\left(v_{i}\right)+\lambda\left(\frac{\partial l_{i}}{\partial p^{*}} \frac{\partial p^{*}}{\partial \pi_{i}}+\frac{\partial l_{i}}{\partial \pi_{i}}\right)=0 \\
& \left\{\begin{array}{l}
\frac{\partial \Lambda}{\partial \pi_{i}}=c_{i}^{\prime}(\cdot)+\pi_{i} \xi_{i} f^{\prime}\left(v_{i}\right)+\lambda=0, \quad \pi_{i} \geq 0 \\
\frac{\partial \Lambda}{\partial \pi_{i}} \pi_{i}=0, \quad v_{i} \geq 0 \\
\frac{\partial \Lambda}{\partial \pi_{i}} v_{i}=0, \quad i=1,2, \cdots, n \\
\frac{\partial \Lambda}{\partial \lambda}=\sum_{i=1}^{n} v_{i}+l_{i}\left(p^{*}, \pi_{i}\right)-E=0 .
\end{array}\right.
\end{aligned}
$$

Proposition 3 When under the case of enterprises perfect compliance, meeting the requirement of implementing the same monitoring cost for all enterprises, which represents $\mu_{i}=\mu_{j}$, and $i \neq j(i, j=1,2, \cdots, n)$, or when $f^{\prime \prime}(0)=0$, carbon emission trading permission may lead socioeconomic costs to achieve cost efficiency.

Proof When under the situation of enterprises perfect compliance, which expresses that there are $v_{i}=0, \xi_{i}=0$ for enterprise $i, \pi_{i}>0$, Equation (21) can be written as

$$
\frac{\partial \Lambda}{\partial \pi_{i}}=c_{i}^{\prime}(\cdot)+\frac{\mu_{i}}{2 \partial l_{i} / \partial \pi_{i}}+\lambda=0, \quad i=1,2, \cdots, n .
$$

Suppose the enterprises are on a perfect competition emission trading market, the optimal conditions for enterprise $i$ is $-c_{i}{ }^{\prime}(\cdot)=p^{*}$, the supervision probability is $i$ is $-c_{i}{ }^{\prime}(\cdot)=p^{*}$, when $v_{i}=0$, Equation $(25)$ can be written as

$$
-p^{*}+\frac{\mu_{i}}{2 \partial l_{i} / \partial \pi_{i}}=-\lambda, \quad i=1,2, \cdots, n
$$

All the enterprise need to meet

$$
-p^{*}+\frac{\mu_{i}}{\partial l_{i} / \partial \pi_{i}}=-p^{*}+\frac{\mu_{j}}{\partial l_{j} / \partial \pi_{j}}=-\lambda, \quad i \neq j, \quad i, j=1,2, \cdots, n .
$$

When $v_{i}=0$, bringing $p^{*}=\pi_{i} f^{\prime}(0), \partial l_{i} / \partial \pi_{i}=f^{\prime}(0) / \pi_{i} f(0)$, and $i \neq j, i, j=1,2, \cdots, n$ into Equation (27) so that it turns out to be

$$
-p^{*}+\mu_{i} \frac{\pi_{i} f(0)}{f^{\prime}(0)}=-p^{*}+\mu_{j} \frac{\pi_{j} f(0)}{f^{\prime}(0)}, \quad i \neq j, \quad i, j=1,2, \cdots, n .
$$

Taking the place of $\pi_{i}$ and $\pi_{j}$ of Equation (28) by $p^{*} / f^{\prime}(0)$, it comes out as

$$
-p^{*}+\mu_{i} \frac{p^{*} f(0)}{f^{\prime}(0)^{2}}=-p^{*}+\mu_{j} \frac{p^{*} f(0)}{f^{\prime}(0)^{2}}, \quad i \neq j, \quad i, j=1,2, \cdots, n .
$$

The equations mentioned above is true only in the restrictions of $\mu_{i}=\mu_{j}$ or $f^{\prime \prime}(0)=0$. In conclusion, proposition 3 has been proved.

Proposition 4 Under the condition of enterprises imperfect compliance, when meeting the requirements of $\mu_{i}=0, \xi_{i}=\xi_{j}$, and $f\left(v_{i}\right) f^{\prime \prime}\left(v_{i}\right)=2\left(f^{\prime}\left(v_{i}\right)\right)^{2}$ as well, carbon emission trading permission could afford socioeconomic costs to get optimal cost efficiency. 
Proof When in the situation of enterprises imperfect compliance, there are $v_{i}>0$ for them, simultaneous equations of (21) and (22) are

$$
\frac{\mu_{i}+\xi_{i} f\left(v_{i}\right)}{\frac{\partial l_{i}}{\partial p^{*}} \frac{\partial p^{*}}{\partial \pi_{i}}+\frac{\partial l_{i}}{\partial \pi_{i}}}=\pi_{i} \xi_{i} f^{\prime}\left(v_{i}\right), \quad i=1,2, \cdots, n .
$$

For in the competitive carbon emission trading market, the optimal emission condition of enterprise $i$ is $-c_{i}{ }^{\prime}(\cdot)=p^{*}$, then the generated equilibrium price $p^{*}=\pi_{i} f^{\prime}\left(v_{i}\right)$, Equation (22) can be written as below:

$$
\left(-1+\xi_{i}\right) p^{*}=-\lambda, \quad i=1,2, \cdots, n .
$$

There is no denying that we can infer from Equation (31), if regulators are inclined to make socioeconomic costs obtain the optimal cost efficiency in the competitive carbon emission trading market, there need to be:

$$
\xi_{i}=\xi_{j}, \quad i=1,2, \cdots, n .
$$

When $\xi_{i}=\xi_{j}, \mu_{i} \neq \mu_{j}, i \neq j, i, j=1,2, \cdots, n$, Equation (30) can be expressed as

$$
\frac{\mu_{i}+\xi f\left(v_{i}\right)}{2 \partial l_{i} / \partial \pi_{i}}=\pi_{i} \xi f^{\prime}\left(v_{i}\right), \quad i=1,2, \cdots, n
$$

Put $\partial l_{i} / \partial \pi_{i}=f^{\prime}\left(v_{i}\right) / \pi f\left(v_{i}\right)$ into Equation (33), it comes out as

$$
\left(\mu_{i}+\xi f\left(v_{i}\right)\right) \frac{f\left(v_{i}\right)}{\left(f^{\prime}\left(v_{i}\right)\right)^{2}}=2 \xi
$$

What makes the above equation true is only when $\mu_{i}=0$ and $f\left(v_{i}\right) f^{\prime \prime}\left(v_{i}\right)=2\left(f^{\prime}\left(v_{i}\right)\right)^{2}$. To crown it all, Proposition 4 has been proved.

Propositions 3 and 4 have reflected a common feature. Put it widely, with respect to command-and-control implementation of carbon emission standard, the implementation of carbon emission trading permission not merely prompt regulators to render socioeconomic costs the optimal cost efficiency in the lower enforcement costs, but also promote utilization ratio of resources and allocation efficiency, meanwhile, in the competitive carbon emission trading market, carbon emission permits have the functions of distribution and direction of price, which explains the policy of carbon emission trading permission is characterized for its economic stimulation and market flexibility at the same time.

\subsection{Analysis of the Optimal Cost Efficiency Decision-Making in Carbon Tax 4.3.1 Analysis of Pricing Carbon Tax Under Behaviors of Enterprises Perfect Compliance}

We can reach the following conclusion from the optimal abatement strategy under the condition of carbon tax levied according to chapter 3.3.

Proposition 5 Taking abatement costs, monitoring costs and enforcement costs into account simultaneously, only when regulators set carbon tax as $t_{i}=\pi_{i} f^{\prime}\left(v_{i}\right)$, their enforcement costs of policy will be the lowest, ensuring that enterprises can fully comply with as well. 
Proof We are able to know $r_{i}=0$ and $e_{i}=e_{i}\left(\pi_{i} f^{\prime}\left(e_{i}-r_{i}\right)\right)$ in the light of Equations (5) and Equations (6), assume that when $t_{i}>\pi_{i} f^{\prime}\left(v_{i}\right)$ and is fixed, which is to say, the sum of monitoring costs $\mu_{i} \pi_{i}$ remain unchanged. However, we maintain that $t_{i}$ has been decreased, which makes $t_{i}=\pi_{i} f^{\prime}\left(e_{i}-r_{i}\right)$, then enterprise $i$ will select compliant behaviors and let $r_{i}=e_{i}$, but when there does not exist sanctioning costs, which shows the time when $\xi_{i} \pi_{i} f\left(e_{i}-r_{i}\right)$ becomes 0 . At this very moment, we can impel the sum of enforcement costs to reduce; suppose that $t_{i}<\pi_{i} f^{\prime}\left(v_{i}\right)$, in that it turns out to be $r_{i}=0$ and $e_{i}=e_{i}\left(\pi_{i} f^{\prime}\left(e_{i}-r_{i}\right)\right)$, when enterprise $i$ choose to fully comply with, namely $e_{i}=e_{i}\left(t_{i}\right)$. For the time being, regulators will reduce the frequency of supervision step by step, which gradually approximate to $\pi_{i} f^{\prime}\left(e_{i}-r_{i}\right)$. During the process, enterprises emissions and compliant behaviors remain the same, but for the reduction of leads the sum of monitoring costs decrease, it reaches the minimum when $t_{i}=\pi_{i} f^{\prime}\left(e_{i}-r_{i}\right)$. Consequently, it has to meet the requirement of $t_{i}=\pi_{i} f^{\prime}\left(e_{i}-r_{i}\right)$ if we would minimize the sum of expected enforcement costs. Besides, the minimization of total monitoring costs can be achieved by means of individual penalty as high as possible, which expresses that the sum of increased monitoring costs is established above the level of individual monitoring cost, the increase of total sanctioning costs is at the cost of individual firm penalty.

What needs to be laid considerable emphasis on is that regulators keep imperfect information regarding abatement costs of enterprises during the whole process, enforcement costs in carbon tax policy are able to acquire minimization through the choice of $t_{i}=\pi_{i} f^{\prime}\left(e_{i}-r_{i}\right)$. In addition, both monitoring and sanctioning costs have been well received as uncertain in this proposition, the sum of increased monitoring costs is established above the level of individual monitoring cost, the increase of total sanctioning costs is at the cost of individual firm penalty. This conclusion depends on three assumptions which differ from generally motivational environmental policy: 1) There exist costs levying fines from non-compliance enterprises, the basic concepts which can guide enterprises to fully comply with are to avoid these costs; 2) Without consideration about sanctioning costs, Proposition 5 will not be tenable, because whether enterprises perfect compliance or not makes no sense; 3) Allowing regulators to make choices of enterprises taxes freely, but other relevantly assumptive tax rates are always settled ${ }^{[19]}$.

\subsubsection{The Optimal Carbon Tax Strategy in Unsteady Marginal Penalty}

This part mainly discusses how to design a carbon tax policy under conditions of unsteady marginal penalty and unknown to the individual enterprise emissions so as to make socioeconomic costs minimized. In order to enable socioeconomic costs to attain cost efficiency, the optimal planning by regulators is as below:

$$
\begin{aligned}
& \min _{\left(e_{i}, r_{i}\right)} \leq c\left(e_{i}, \varepsilon_{i}\right)+t_{i} r_{i}+\pi_{i} f\left(e_{i}-r_{i}\right) \\
& \text { s.t. } \quad e_{i}-r_{i} \geq 0, \quad r_{i} \geq 0
\end{aligned}
$$

When enterprise $i$ that does not fully comply with will pick its marginal abatement costs of carbon emissions equal to that of marginal penalty, thus, the optimal emissions choice of this 
enterprise is

$$
e_{i}= \begin{cases}e\left(t_{i}\right) \mid c^{\prime}\left(e_{i}\right)+t_{i}=0, & \text { if } t_{i} \leq \pi_{i} f^{\prime}\left(e_{i}-r_{i}\right) \\ e\left(\pi_{i} f^{\prime}\left(e_{i}-r_{i}\right)\right) \mid c^{\prime}\left(e_{i}\right)+\pi_{i} f^{\prime}\left(e_{i}-r_{i}\right)=0, & \text { if } t_{i}>\pi_{i} f^{\prime}\left(e_{i}-r_{i}\right)\end{cases}
$$

Among which, $e_{i}=e(x)$ is the actual carbon emissions function of enterprise $i$. The objective of this study is to set up a specific carbon tax policy and implementation strategy for purpose of making total socioeconomic costs the lowest, the optimal programming of regulators by this time is

$$
\begin{array}{ll}
\min _{\substack{\left(s_{1}, s_{2} \cdots, s_{n}\right) \\
\left(\pi_{1}, \pi_{2}, \cdots, \pi_{n}\right)}} & \sum_{i=1}^{n} c_{i}\left(e_{i}, \varepsilon_{i}\right)+\mu_{i} \pi_{i}+\pi_{i} \xi_{i} f\left(v_{i}\right) \\
\text { s.t. } & \left\{\begin{array}{l}
e_{i}=e\left(\tau_{i}, \pi_{i}\right), \\
\sum_{i=1}^{n} e_{i}=E, \\
e_{i} \leq r_{i}, \quad \forall i=1,2, \cdots, n .
\end{array}\right.
\end{array}
$$

The abatement costs of enterprises can be represented as $\sum_{i=1}^{n} c_{i}\left(e_{i}, \varepsilon_{i}\right)$, monitoring costs expressed as $\sum_{i=1}^{n} \mu_{i} \pi_{i}$, and sanctioning costs written as $\sum_{i=1}^{n} \xi_{i} \pi_{i} f\left(e_{i}-r_{i}\right)$. Assuming that penalty function $f\left(e_{i}-r_{i}\right)$ is an exogenous variable for regulators, then Lagrangian function which set by regulators for solving the problem is

$$
\Lambda=\sum_{i=1}^{n}\left(c_{i}\left(e_{i}, \varepsilon_{i}\right)+\mu_{i} \pi_{i}+\xi_{i} \pi_{i} f\left(e_{i}-r_{i}\right)\right)+\lambda\left[\sum_{i=1}^{n} e_{i}-E\right] .
$$

In line with the requirements of Kuhn-Tucker:

$$
\left\{\begin{array}{l}
\frac{\partial \Lambda}{\partial r_{i}}=c_{i}^{\prime}\left(e_{i}\right) \frac{\partial e_{i}}{\partial r_{i}}+\xi_{i} \pi_{i} f^{\prime}\left(e_{i}-r_{i}\right)\left(\frac{\partial e_{i}}{\partial r_{i}}-1\right)+\lambda \frac{\partial e_{i}}{\partial r_{i}}=0 \\
\frac{\partial \Lambda}{\partial \pi_{i}}=c_{i}^{\prime}\left(e_{i}\right) \frac{\partial e_{i}}{\partial \pi_{i}}+\mu_{i}+\xi_{i}\left(f\left(e_{i}-r_{i}\right)+\pi_{i} f^{\prime}\left(e_{i}-r_{i}\right) \frac{\partial e_{i}}{\partial \pi_{i}}\right)+\lambda \frac{\partial e_{i}}{\partial \pi_{i}}=0 \\
\frac{\partial \Lambda}{\partial \lambda}=\sum_{i=1}^{n} e_{i}-E=0, \quad \lambda \geq 0, \quad \forall i=1,2, \cdots, n .
\end{array}\right.
$$

We can draw the following conclusion from the above analysis:

Proposition 6 When the level of carbon tax rate is no lower than the division of increased marginal sanctioning costs through driving down reported discharge volume by enterprises and decreased marginal monitoring costs during lowering supervision probability, which enable socioeconomic costs to achieve the optimal cost efficiency, that is to satisfy:

$$
t_{i} \geq \frac{\mu_{i} f^{\prime \prime}(0)}{\xi_{i} f^{\prime}(0)}
$$

Proof As enterprises fully comply with, which indicates, it is inferred from Equation (38):

$$
\frac{\partial e_{i} / \partial r_{i}}{\partial e_{i} / \partial \pi_{i}}=\frac{\xi_{i} \pi_{i} f^{\prime}\left(e_{i}-r_{i}\right)}{-\mu_{i}-\xi_{i} f\left(e_{i}-r_{i}\right)}
$$


Because the optimal discharge requirement of enterprise in the condition of emission standard is $-C_{i}^{\prime}\left(e_{i}\right) \leq \pi_{i} f^{\prime}\left(e_{i}-r_{i}\right)^{[20]}$ so the partial derivatives of and from both sides are

$$
\begin{aligned}
& \frac{\partial e_{i}}{\partial \pi_{i}}=\frac{-f^{\prime}\left(e_{i}-r_{i}\right)}{C^{\prime \prime}{ }_{i}\left(e_{i}\right)+\pi_{i} f^{\prime \prime}\left(e_{i}-r_{i}\right)}<0, \\
& 0<\frac{\partial e_{i}}{\partial r_{i}}=\frac{\pi_{i} f^{\prime \prime}\left(e_{i}-r_{i}\right)}{C^{\prime \prime}{ }_{i}\left(e_{i}\right)+\pi_{i} f^{\prime \prime}\left(e_{i}-r_{i}\right)}<1 .
\end{aligned}
$$

Because when stated discharge in carbon emission standard is equivalent to carbon emissions of enterprises, inspecting resources which taken advantage of by regulators shall achieve the optimal allocation, enforcement costs have the characteristic of highest cost efficiency, which is to make $-c_{i}^{\prime}\left(e_{i}\right)=-c_{i}^{\prime}\left(s_{i}\right) \leq \pi_{i} f^{\prime}(0)$ come true ${ }^{[10]}$, in the meantime, based on the condition that when $t_{i}=\pi_{i} f^{\prime}\left(e_{i}-r_{i}\right)$, the enforcement costs are the lowest. Put Equations (42), (43) into (41) so that we are able to get the result as

$$
{\frac{\partial e_{i} / \partial r_{i}}{\partial e_{i} / \partial \pi_{i}}}_{e_{i}=r_{i}}=\frac{\pi_{i} f^{\prime \prime}\left(e_{i}-r_{i}\right)}{-f^{\prime}\left(e_{i}-r_{i}\right)}=\frac{\xi_{i} \pi_{i} f^{\prime}\left(e_{i}-r_{i}\right)}{-\mu_{i}-\xi_{i} f\left(e_{i}-r_{i}\right)}
$$

Due to the results of $f(0)=0, f(0) \rightarrow 0^{+}, \pi_{i} \geq 0$ which acquired from above, hence, there is: $\frac{\pi_{i} f^{\prime \prime}(0)}{-f^{\prime}(0)}=\frac{\xi_{i} t_{i}}{-\mu_{i}-\xi_{i} f(0)}=\frac{\xi_{i} t_{i}}{-\mu_{i}}$, so that it is obtained $t_{i}=\frac{\pi_{i} \mu_{i} f^{\prime \prime}(0)}{\xi_{i} f^{\prime}(0)}$. From the above, Proposition 6 has been proved.

\section{Comparative Analysis of the Optimal Cost Efficiency}

From the above research, we have analyzed the optimal cost efficiency decision-making in the implementations of both two different types of carbon emission policy instruments by regulators under the control of total carbon emissions. During the course of carrying out the policy of carbon emission standard, regulators are about to make socioeconomic costs get the optimal cost efficiency by methods of administrative means, such as adjusting monitoring strength and penalties for violations, while in the policy of carbon emission trading permission, in order to achieve the same goal, the lower monitoring costs and sanctioning costs are implemented by regulators. However, for this issue - which has the advantages of higher cost efficiency in these two carbon emission policy instruments under the control of total carbon emissions this paper has compared cost efficiency of those policy instruments in the case of imperfect information, the exact outcome has been shown in Proposition 7.

Proposition 7 With the target of realizing total carbon emissions being controlled, when enterprises grasp imperfect information towards regulators, the implementation of carbon emission trading permission is much more cost efficient than that of carbon emission standard.

Proof Assume that socioeconomic costs are $c^{S}$, which covers $n$ enterprises' abatement costs $c^{E}$ and regulators' enforcement $\operatorname{costs} c^{G}$, then there exist equations as follows:

$$
\begin{aligned}
& c_{\text {standard }}^{S}=c_{\text {standard }}^{E}+c_{\text {standard }}^{G}=\sum_{i=1}^{n} c_{i}\left(e_{i}\right)+\sum_{i=1}^{n}\left[\mu_{i} \pi_{i}+\xi_{i} \pi_{i} f\left(e_{i}-s_{i}\right)\right], \\
& c_{\text {permit }}^{S}=c_{\text {permit }}^{E}+c_{\text {permit }}^{G}=\sum_{i=1}^{n}\left[c_{i}\left(v_{i}+l_{i}\left(p^{*}, \pi_{i}\right)\right)\right]+\sum_{i=1}^{n}\left[\mu_{i} \pi_{i}+\pi_{i} \xi_{i} f\left(v_{i}\right)\right] .
\end{aligned}
$$


For the purpose of facilitating comparisons of cost efficiency, this paper has classified $n$ reduction enterprises, which divided into $n_{1}$ enterprises with good reduction capability $\theta_{1}$ and $n_{2}$ enterprises with weak reduction capability $\theta_{2}$, what's more, $\theta_{2}>\theta_{1}, n_{1}+n_{2}=n$. Under the given abatement standard $s$, there is $c\left(s, \theta_{2}\right)>c\left(s, \theta_{1}\right)$. Due to the imperfect information, abatement costs of enterprises that supervised by regulators in emission standard are no less than that in carbon emission trading permission ${ }^{[12]}$, therefore, we are just in need to compare enforcement costs in carbon emission standard and carbon emission trading permission by regulators here. Regulators have made the optimal distribution for carbon emission permits under the condition of carbon emission trading permission and minimized the sum of marginal abatement costs so as to accomplish the abatement target in total carbon emissions controlled. Suppose that equilibrium price of carbon emission permits is $p\left(\theta_{1}, \theta_{2}, L\right)$ in a competitive carbon emission trading market, then balanced amount of carbon emission standard which set up by regulators for these two types of reduction enterprises can be expressed as and. Because the way that regulators directed enterprises to comply with the highest cost efficiency is to equal every single enterprise's monitoring probability, with the underlying assumption that $\pi_{1}=\pi_{2}=\pi=p\left(\theta_{1}, \theta_{2}, L\right) / f^{\prime}(0)$, then there are

$$
\begin{aligned}
& -c_{e 1}\left(s_{1}, \theta_{1}\right) / f^{\prime}(0)=-c_{e 2}\left(s_{2}, \theta_{2}\right) / f^{\prime}(0)=p\left(\theta_{1}, \theta_{2}, L\right) / f^{\prime}(0) \\
\Rightarrow & -c_{e 1}\left(\overline{s_{1}}, \theta_{1}\right)=-c_{e 2}\left(\overline{s_{2}}, \theta_{2}\right)=p\left(\theta_{1}, \theta_{2}, L\right) .
\end{aligned}
$$

Each enterprise' enforcement costs by regulators can be set as $\varphi$, which takes in monitoring costs and sanctioning costs of it. Make $c^{O}$ as optimal costs, then the optimal enforcement costs in the implementation of carbon emission trading permission can be written as:

$$
\begin{aligned}
c_{\text {permit }}^{O-G} & =\sum_{i=1}^{n}\left[c_{i}\left(v_{i}+l_{i}\left(p^{*}, \pi_{i}\right)\right)\right]+\sum_{i=1}^{n}\left[\mu_{i} \pi_{i}+\pi_{i} \xi_{i} f\left(v_{i}\right)\right]=\varphi n \times p\left(\theta_{1}, \theta_{2}, L\right) / f^{\prime}(0) \\
& =\varphi n \times p\left(\theta_{1}, \theta_{2}, L\right) / f^{\prime}(0)=\varphi n \times\left[-c_{e 2}\left(\overline{s_{2}}, \theta_{2}\right)\right] / f^{\prime}(0) .
\end{aligned}
$$

Under the carbon emission standard, the amount of carbon emission standard which set up by regulators for two sorts of reduction enterprises meets both $s_{1}+s_{2}=E=L$ and $\bar{s}<\max \left(s_{1}, s_{2}\right)$. Since regulators are not able to discern from types of reduction enterprises effectively in the case of imperfect information, as a result, when $s_{1} \neq \overline{s_{1}}$ and $s_{2} \neq \overline{s_{2}}$, for the sake of guiding enforcement costs obtain the optimal cost efficiency by regulators in carbon emission standard, the implementation of unified monitoring probability for different sorts of abatement enterprises is extremely indeed in need, except that, emission standard is required to set up in accordance with enterprise of the biggest marginal abatement cost, which satisfies

$$
\pi_{1}=\pi_{2}=\max \left[-c\left(s_{1}, \theta_{1}\right) / f^{\prime}(0),-c\left(s_{2}, \theta_{2}\right) / f^{\prime}(0)\right] .
$$

Then the optimal enforcement costs in the implementation of carbon emission standard can be expressed as

$$
\begin{aligned}
c_{\text {standard }}^{O-G} & =\sum_{i=1}^{n} c_{i}\left(e_{i}\right)+\sum_{i=1}^{n}\left[\mu_{i} \pi_{i}+\xi_{i} \pi_{i} f\left(e_{i}-s_{i}\right)\right] \\
& =\varphi n \times \max \left[-c_{e 1}\left(s_{1}, \theta_{1}\right),-c_{e 2}\left(s_{2}, \theta_{2}\right)\right] / f^{\prime}(0) .
\end{aligned}
$$


The outcome is able to be got through comparing Equations (47) and (49): $c_{\text {permit }}^{O-G}<$ $c_{\text {standard. }}^{O-G}$. When $s_{1}=\overline{s_{1}}, s_{2}=\overline{s_{2}}$, there is $c_{\text {permit }}^{O-G}=c_{\text {standard }}^{O-G}$, so is $c_{\text {permit }}^{O-G} \leq c_{\text {standard }}^{O-G}$. As $c_{\text {permit }}^{E} \leq c_{\text {standard }}^{E}$, so $c_{\text {permit }}^{S} \leq c_{\text {standard }}^{S}$. To sum up, proposition 7 has been proved.

\section{Conclusions}

By establishing regulatory and optimum planning model whilst taking into account the abatement costs, monitoring costs and sanctioning costs, besides that, on the premise of complying strictly with the objective of total carbon emissions controlled, this paper, from the perspective of cost efficiency, analyzes the optimal supervision decisions of regulators under three forms of carbon emission reduction policy tools, and based on which, it also compares the cost efficiency of carbon emission trading permission and standard for carbon dioxide emission on the perquisite of total carbon emissions controlled. Meanwhile, the paper discusses about the optimal strategy for implementing carbon tax based on non-constant marginal sanctioning costs. It is found in the research that: 1) Regulators may work out corresponding optimal cost efficiency decisions as per enterprise's diverse emission reduction behavior, in the hope of minimizing socioeconomic costs, among which, under the condition of incomplete information, implementing carbon emission trading permission achieves higher cost efficiency than carbon emission standard. This demonstrates that the carbon emission trading mechanism can bring about the optimal allocation of supervision resources, environmental resources and social resource, develop the self-organized incentive mechanism for carbon emission trading permission as well so that improve the enthusiasm of enterprises emission reduction and effectively bring down the control cost of supervision departments. Consequently, the mechanism shows remarkable superiority and flexibility than carbon emission standard. 2) When the penalty function is the convex one that indicates strict increasing, the tax rate level based on observance of enterprises shall not be lower than the quotient of marginal penalty costs and marginal monitoring costs. If enterprises fail to observe incompletely, the optimal strategy is that the marginal costs which varied in emission standard by regulators equals to those with variations in monitoring frequency.

It is found through the above research that it is feasible for the actual implementation of either trading mechanism of carbon emission trading or carbon tax mechanism. If on the strength of perfect information and without uncertainty, these two sorts of market-based policy tools are able to attain the same effect, that is, both of them can lead to the the minimized total abatement costs of enterprises. However, if, in the case of incomplete information and with several uncertainties, the above two mechanisms shall have distinct effects and functions. Given China's inadequate supervision and law enforcement resources, it is a must to consider the cost efficiency for implementing policies for purpose of raising efficiency of carbon emission control. As a consequence, it is of necessity to regard policy-incurred trading costs as an indispensable influencing factor to make a comparison of cost-benefit of carbon emission reduction policy instruments, which will provide scientific basis and reference for policy selection. Hence, system for carbon emission trading compatible with China's circumstances is supposed to be duly established in accordance with national's actually developmental situations. We shall also design and exploit the carbon emission trading platform, improve the mechanisms for price adjustment 
and control, emission rights reservation, debit and credit, and its like, formulate related laws and regulations for the definition, change and realization of main rights and obligations of each party during the operation of carbon trading system, and create more demands for carbon trading markets by means of legislation while guide the real economy to achieve low-carbon transition.

\section{References}

[1] Song D Y, Shi C. Research on environment-friendly behavior, information disclosure and the pigouvian tax. China Population, Resources and Environment, 2012, 22(6): 7-11.

[2] Jin S, Sheng Z H, Du J G. Study on supervision mechanism in regional emissions trading system. China Population, Resources and Environment, 2011, 21(3): 14-19.

[3] Xu S C, Long R Y. Optimal choice of environmental policy instruments considering eco-industry development. Operations Research and Management Science, 2012, 21(5): 187-192.

[4] Bromley D W. Handbook of environmental economics. Oxford, U. K, Cambridge, Mass, USA: Blackwell, 1995.

[5] Maler K G and Vincent J R. Handbook of environmental economics. Amsterdam: North-Holland/Elsevier, 2003.

[6] Harford J D. Firm behaviour under imperfectly enforceable pollution standards and taxes. Environmental Economics and Management, 1978(5): 26-43.

[7] Helfand G. Standards versus standards: The effects of different pollution restrictions. American Economic Review, 1991, 81: 622-634.

[8] Malik A. Enforcement cost and the choice of policy instruments for controlling pollution. Economic Inquiry, 1992, 30: 714-721.

[9] Hahn R, Axtell R. Reevaluating the relationship between transferable property rights and command and control regulations. Regulatory Economics, 1995, 8: 125-148.

[10] Stranlund J K. The regulatory choice of noncompliance in emissions trading programs. Environmental and Resource Economics, 2007, 38(1): 99-117.

[11] Arguedas C. To comply or not to comply? Pollution standard setting under costly monitoring and sanctioning. Environmental and Resource Economics, 2008, 41: 155-168.

[12] Aldy J, Krupnick A, Newell R, et al. Designing climate mitigation policy. Resource for the Future, Discussion Paper, 2009, 8-16.

[13] Chávez C A, Villena M G, Stranlund J K. The choice of policy instruments to control pollution under costly enforcement and incomplete information. Applied Economics, 2009, 12(2): 207-227.

[14] Caffera M, Chávez C A. The cost-effective choice of policy instruments to cap aggregate emissions with costly enforcement. Environmental and Resource Economics, 2011, 50: 531-557.

[15] Li X S, Song M L, An Q X. Environmental regulation cost based on the environmental technology: Evidence from provincial level data. China Population, Resources and Environment, 2013, 23(6): 111-116.

[16] Xu S C, He Z X, Long R Y. Comparative research on environmental policy instruments: Enterprise emission abatement perspective. Systems Engineering — Theory \& Practice, 2012, 32(11): 2351-2362.

[17] Sandmo A. Efficient environmental policy with imperfect compliance. Envionmental Resource Economics, 2002, 23: 85-103.

[18] Stranlund J K, Chávez C A, Villena M G. The optimal pricing of pollution when enforcement is costly. Environmental Economics and Management, 2009, 58: 183-191.

[19] Li X F, Zhang Z S, Gao Y. Research on optimal implementation of carbon tax considering cost effectiveness. Journal of Systems Engineering, 2014, 5: 680-688.

[20] Anthony H. Implementing environmental regulation: Enforcement and compliance. Regulatory Economics, 2000, 17: 107-129. 